\title{
FORMAÇÃO DE PROFESSORES: ESCLARECIMENTO E AUTORREFLEXÃO PARA UMA EDUCAÇÃO EMANCIPATÓRIA COM BASE EM THEODOR ADORNO
}

\author{
TEACHER TRAINING: CLARIFICATION AND SELF- \\ REFLECTION FOR EMANCIPATORY EDUCATION BASED ON \\ THEODOR ADORNO
}

\section{FORMACIÓN DE PROFESORES: ESCLARECIMIENTO Y AUTORREFLEXIÓN PARA UNA EDUCACIÓN EMANCIPADORA CON BASE EN THEODOR ADORNO}

\author{
Nidal Afif Obeid Freitas ${ }^{1}$ \\ https://orcid.org/0000-0002-5915-1212 \\ Luciana Maria Lunardi Campos Campos ${ }^{2}$ \\ https://orcid.org/0000-0003-3258-0444 \\ 1 Universidade do Estado do Pará, Conceição do Araguaia, Pará - Brasil. E-mail: \\ nidalfreitas@yahoo.com.br. \\ 2 Universidade Estadual Paulista, Botucatu, São Paulo - Brasil. E-mail: luciana.lunardi- \\ campos@unesp.br.
}

\section{Resumo}

Este artigo tem por objetivo apresentar contribuições epistemológicas do pensamento de Theodor Adorno para a reflexão sobre formação docente emancipatória a partir dos conceitos de esclarecimento e autorreflexão. Tendo a perspectiva dialética como referência para pensar a sociedade e suas contradições, bem como a formação do professor, pretende-se evidenciar que, apesar do desenvolvimento do capitalismo, um sistema apto a impedir as tentativas de transformações equitativas, há a possibilidade de desenvolvimento de uma atitude de autocrítica e de resistência que pode ser posta em ação pelos indivíduos por meio do esclarecimento e da autorreflexão. Formar o docente em uma proposta emancipatória requer a adoção de um projeto consistente que leve a superar a adaptação e consiga desvelar as contradições sociais, a fim de que o indivíduo possa transitar conscientemente no mundo, com o mundo e para a sua transformação.

Palavras-chave: Teoria Crítica. Educação. Formação de Professores. 


\begin{abstract}
This article aims to present the epistemological contributions of Theodor Adorno's thought to the reflection of emancipatory teacher education, based on two concepts, enlightenment and self-reflection. Taking the dialectical perspective as a reference to think about society and its contradictions, as well as teacher education, it is intended to show that, despite the development of capitalism, a system capable of preventing attempts at equitable transformations, there is the possibility of developing an attitude of self-criticism and resistance, which can be put into action by individuals through enlightenment and selfreflection. Training the teacher in an emancipatory proposal requires the adoption of a consistent project that leads to overcome adaptation, unveil social contradictions so that the individual can consciously transit in the world, with the world and for its transformation.
\end{abstract}

Keywords: Critical Theory. Education. Teacher Training.

\title{
Resumen
}

Este artículo tiene como objetivo presentar las contribuciones epistemológicas del pensamiento de Theodor Adorno para la reflexión sobre la formación docente emancipadora desde los conceptos del esclarecimiento y de la autorreflexión. Considerándose la perspectiva dialéctica como referencia para pensar sobre la sociedad y sus contradicciones, así como la formación del profesor, se pretende demostrar que, a pesar del desarrollo del capitalismo, un sistema capaz de impedir intentos de transformaciones equitativas, hay la posibilidad del desarrollo de una actitud de autocrítica y resistencia que se puede poner en acción por los individuos mediante el esclarecimiento y la autorreflexión. Capacitar al docente a una propuesta emancipadora requiere la adopción de un proyecto consistente que pueda superar la adaptación e revelar contradicciones sociales para que el individuo pueda transitar conscientemente en el mundo, con el mundo y para su transformación.

Palabras clave: Teoría Crítica. Educación. Formación de Professores.

\section{Introdução}

Este artigo constitui parte da tese de doutorado que teve por objeto a configuração de um estágio supervisionado fundamentado em uma proposta de formação emancipatória sob a perspectiva de Theodor Adorno. Ter presenciado a barbárie dos regimes totalitários conduziu Adorno à crítica da sociedade e à elaboração da teoria crítica, juntamente com Horkheimer. Sua formação filosófica e a publicação da Dialética do Esclarecimento ${ }^{1}$ o levou em direção à teoria crítica da sociedade (PUCCI, 1994).

No período de 1930 a 1970, os autores frankfurtianos clássicos ${ }^{2}$ escreveram sobre temas filosóficos, culturais, sociais, estéticos, psicológicos. "E mesmo permanecendo nos

\footnotetext{
${ }^{1}$ Escrita em 1947, obra fundamental da "teoria crítica" das ciências sociais, sendo seus autores, Adorno e Horkheimer, da primeira geração da "Escola de Frankfurt".

${ }^{2}$ Fundadores da teoria crítica da Escola de Frankfurt tal concebida por Marcuse, Horkheimer e Adorno.
} 
horizontes do pensamento marxista, dialogaram crítica e intensamente com Kant, Hegel, Weber, Nietzsche e Freud" (PUCCI, 2001, p. 3).

Pensar a emancipação e a formação de professores em Adorno requer trazer a ideia lançada por Kant sobre o esclarecimento como meio de o homem superar a menoridade para alcançar a verdadeira liberdade. O pensamento de Imanuel Kant sobre a maioridade e autonomia humana influenciou fortemente as teorias pedagógicas do século XIX, visando a encorajar, pela educação, a realização desses princípios.

Adorno buscou, nos campos da sociologia e filosofia, elementos que pudessem responder à desumanização do humano. Sua teoria é referência para se pensar a adoção de uma pedagogia crítica que atenda às necessidades de uma educação que priorize a relação crítica ensino/problematização/indivíduo/sociedade.

Em Educação e emancipação (2010), Adorno chama atenção para a resposta de Kant sobre esclarecimento ao definir a "[...] menoridade ou tutela e, deste modo, também a emancipação, afirmando que este estado de menoridade é auto inculpável quando sua causa não é a falta de entendimento, mas a falta de decisão e coragem de servir-se do entendimento sem a orientação de outrem" (ADORNO, 2010, p. 169). Ele alerta que os homens devem se emancipar da tutela feita pelos outros, ousando fazer uso público da própria razão.

Seu interesse pela emancipação humana se vincula à obrigação de a educação orientar as novas gerações para que a barbárie não se repita, pois, na visão de Adorno, o retorno da barbárie seria possível, tendo em vista que as condições de opressão, submissão e exploração do homem pelo homem ainda não foram totalmente extintas das sociedades (ADORNO, 2010). De certo modo, emancipação significa o mesmo que conscientização, racionalidade.

A realidade envolve continuamente um movimento de adaptação e a educação seria impotente e ideológica se ignorasse o objetivo de adaptação e não preparasse os homens para se orientarem no mundo, porém ela seria igualmente questionável se ficasse nisso, produzindo nada além de well adjusted people, pessoas bem ajustadas, em consequência do que a situação existente impõe precisamente no que tem de pior (ADORNO, 2010, p. 143).

O esclarecimento e o pensamento autorreflexivo são determinantes na formação educacional para uma educação crítica e emancipatória, pontos iniciais para a ruptura de uma educação para a subserviência. 


\section{Esclarecimento e autorreflexão para uma educação emancipatória}

Esclarecimento em Adorno e Horkheimer (1985) é usado para designar o processo de “desencantamento do mundo" pela racionalização que prossegue na filosofia e na ciência.

O esclarecimento almeja situar a condição do homem de agente histórico de produção das suas condições de vida e da sociedade na qual está inserido e submetido, dando-lhe condições de negar o estabelecido e criar uma consequente práxis social, capaz de intervir para a sua mudança (HORKHEIMER; ADORNO, 1985). Como afirma Ruiz (1984, p. 10), “é enquanto 'produtora de consciência' que a teoria crítica espera participar de 'uma prática emancipadora racionalizante"”.

Adorno e Horkheimer (1985) criticam a forma técnica como o esclarecimento é guiado pela ciência positiva, que busca o controle e a dominação da natureza e do homem. O esclarecimento defendido pelo Iluminismo se afasta do seu projeto originário, transformandose em razão instrumental, que defende a obediência dos processos técnicos e científicos colocados a serviço do sistema econômico e do consumo de seus produtos, caminhando, assim, na contramão da ideia de esclarecimento como guia do homem para o bem-estar.

Na obra Dialética do Esclarecimento, Adorno e Horkheimer (1985) observam que a consciência humana está sendo dominada pela comercialização e banalização dos bens culturais, fenômeno denominado semiformação.

A semiformação é a negação da possibilidade de experiência do sujeito com o objeto. Assim, no processo de sua formação, se o sujeito não se apropriar subjetivamente da cultura, pode ocorrer de o mesmo não valorizar seus sentimentos, sua vontade, sucumbindo ao que possa vir a compreender como mundo real. Desconhecendo o seu papel histórico e social, este sujeito não se dá conta de elaborar seus próprios valores, se deixando conduzir por um mecanismo consumista de objetos materiais e imateriais que contribuem para a alienação deste indivíduo.

$\mathrm{Na}$ interface do conceito de semiformação, Adorno e Horkheimer situam a indústria cultural como promotora da dominação de massa. Zuin (1994) esclarece que Adorno e Horkheimer substituíram o termo cultura de massa por indústria cultural com o intuito de descaracterizar o aspecto de uma cultura que surge espontaneamente das próprias massas. 
Por indústria cultural Adorno (1995) entende a organização da cultura manipulada para a subordinação humana aos interesses econômicos, sob a égide do capitalismo, e que determina o sentido da vida cultural pela lógica racional e estratégica produção econômica. Ela contém os elementos do mundo industrial moderno, nele desempenha o papel de portadora da ideologia dominante e atribui sentido a todo o sistema, repercutindo na formação da mentalidade e na ação dos indivíduos.

Assim, segundo Cohn (1994), a ideologia capitalista e a indústria cultural contribuem eficazmente para obscurecer as relações entre os homens, a ponto de constituir um antiiluminismo. Para Zuin (1994, p. 154), "na sociedade capitalista avançada, a produção e reprodução da cultura, sob a égide da padronização e da racionalidade técnica, obedecem à mesma lógica da produção e reprodução de qualquer outro tipo de mercadoria”.

Nesse sentido, a indústria cultural é vista como a responsável por prejudicar a capacidade humana de agir com autonomia, primando pela manutenção da semiformação. Vilela (2007) considera que

\begin{abstract}
Ao enfatizar o avanço da "semiformação", ocupando todos os espaços educativos da sociedade, ele deslinda a ideologia do sistema de ensino e denuncia graves problemas pedagógicos. Segundo ele, o aumento das oportunidades educacionais não resultou em melhor formação para o povo, pois, ao ter sido agraciado com o direito à escola, a ele foi dada a impressão de tratamento de igualdade. Entretanto, o que ocorre na Educação incorreta (a semiformação) que recebe é a deformação da sua consciência. (VILELA, 2007, p. 9)
\end{abstract}

A análise de Adorno e Horkheimer do modelo avassalador do capitalismo leva seus críticos a caracterizarem seus escritos como pessimistas e desesperançados.

Zuin, Pucci e Ramos-de-Oliveira (2012, p. 53) contestam esse rótulo, pronunciando que:

se no momento atual prevalece a hegemonia da razão instrumental sobre a razão emancipatória, a serviço da propagação da dominação e das injustiças sociais, isso não significa que tenha que ser sempre assim. E é com essa perspectiva que Adorno e Horkheimer finalizam o texto do conceito de esclarecimento, presente na Dialektik der Aufklärung, quando enfatizam a relevância do conceito para a realização de mudanças. 
O esclarecimento e a autorreflexão tratados por Adorno e Horkheimer visam à transformação da sociedade administrada, monopolizadora, o que foi elucidado por Zuin, Pucci e Ramos-de-Oliveira (2012) ao ilustrarem que a grande pretensão do esclarecimento (Aufklärung) era vencer as explicações irracionalistas provenientes dos mitos e substituí-las pelo saber que pudesse ser convertido em algo prático.

Outro rótulo levantado por críticos ao pensamento de transformação da sociedade de Adorno e Horkheimer está direcionado à possibilidade de construção de uma pedagogia crítica a partir da teoria crítica e se esta possui um potencial pedagógico dialético real. Os críticos se fundamentam na ideia de que os pensadores frankfurtianos, embora apresentem uma análise da realidade do processo educacional na sociedade capitalista contemporânea, se mantêm no campo da crítica reprodutivista, da denúncia dos mecanismos de reprodução do capitalismo, contudo não apresentaram instrumentos para superá-lo, não podendo, assim, servir de subsídio para a construção de uma proposta educacional crítica.

Replicando essas críticas, Pucci (1994) defende a tese de que os teóricos frankfurtianos tentaram tanto interpretar a sociedade quanto transformá-la e argumenta que a teoria crítica conserva em sua essência, até os dias atuais, o ideal iluminista de libertar o homem do jugo da repressão, da ignorância e da inconsciência por meio da razão para uma transformação da sociedade.

No esclarecimento existe um potencial pedagógico valoroso para a superação da semiformação. Superar a barbárie é ato decisivo para a sobrevivência da humanidade, "as reflexões precisam, portanto, ser transparentes em sua finalidade humana" (ADORNO, 2010, p. 161). Pucci (1994) nota que, para Adorno, a educação só teria pleno sentido se direcionada para a autorreflexão crítica, condição para a busca da autonomia e autodeterminação do homem, fazendo uso público de sua razão, superando os limites da liberdade trazidos pela barbárie e pela semiformação (PUCCI, 1994).

Para Adorno, a educação deve estar comprometida com a formação para a emancipação e ser espaço de resistência contra a força da indústria cultural que alimenta a semiformação, pois, pelo esclarecimento e pela autorreflexão, é possível desvendar as contradições da sociedade e atingir a "maioridade", a emancipação.

Assim, ao negar a semiformação, Pucci (1994, p. 46) aponta cinco elementos que tornam possível estabelecer uma pedagogia crítica a partir das propostas frankfurtianas de Adorno e Horkheimer, para além de se pensar a escola somente como espaço de reprodução e 
de demandas sociais e assumindo a escola como espaço de esclarecimento e autorreflexão para a emancipação. São elas:

a) a função educativa do refletir, de ir além do repetitivo, do que está dado, pois, no resgate da história viva, é intrinsecamente educativo, forma a sensibilidade, a percepção e o pensamento;

b) o resgate da formação cultural como postulado pedagógico da emancipação sustenta a noção de cultura enquanto força política da sociedade, enquanto um momento político poderoso no processo de dominação, ao contrário da cultura de informes que se transformou pelo processo semicultural da sociedade administrada;

c) a importância da educação e a responsabilidade da escola no processo de “desbarbarização" da sociedade, tendo na autorreflexão crítica seu esteio fundamental;

d) a necessária assimilação do passado como esclarecimento na dimensão hermenêutica das experiências sombrias e desumanas para iluminar, por meio da educação, da psicologia e do esclarecimento, os germens de violência nelas presentes, possibilitando aos educandos o florescimento de forças de resistência e de intervenção consciente no cotidiano de suas vidas, de forma a compreender os erros do passado e não os repetir;

e) o papel social ativo dos intelectuais coletivos no processo de "desbarbarização", da responsabilidade dos intelectuais, individuais e coletivos, pela ação pedagógica e pela participação nos meios de comunicação de massa, não desvinculando suas ações políticas das atividades teóricas, pois a separação entre esses papéis seria o que Horkheimer classificou como pertencente à teoria tradicional.

Esses cinco elementos pontuados por Pucci (1994) mostram que o eixo pedagógico "esclarecimento" denota a importância que a autorreflexão tem para Adorno e Horkheimer na resistência à dominação e na compreensão da contradição inerente a uma sociedade fundada na lógica do capitalismo.

Uma educação crítica capaz de fomentar o processo de resistência à dominação e à massificação continua condição atual para se criar e manter um mundo no qual se possa viver com justiça e dignidade. No lugar da adaptação e do adestramento, a escolarização deve desenvolver a autonomia e a emancipação. 
Ao construir um conceito de autonomia, Adorno aponta ainda outro questionamento, procurando esclarecer não somente "para que" a educação é necessária, mas "para onde" a educação deve conduzir. Se antes o "para que” da educação era compreensível por si mesmo, a indagação do "para onde" de Adorno (2010) causa desconforto e exige reflexões complexas.

Cabe ao professor, ao ensinar, mostrar possibilidades, sair da imposição de uma única forma de trabalhar o conhecimento historicamente acumulado pela humanidade, permitindo ao estudante conhecer diferentes formas de interpretar o conhecimento, visto sob diferentes perspectivas.

Martins (2012) demonstra que a verdadeira educação é a transformação do indivíduo indissociável dos esforços para a transformação da sociedade. Para essa autora, se a tarefa educativa pressupõe um projeto pedagógico, ela pressupõe também um projeto político, em uma relação dialética para uma práxis transformadora na formação de professores a serviço da emancipação humana das condições de exploração da maioria dos indivíduos.

\section{Formação de professores}

Para Pucci e Ramos-de-Oliveira (2007), os professores que, implicados no seu oficio e sua prática, não refletem criticamente acerca da relação entre escola e sociedade acabam por ceder sua condição docente e passam a ser meros assistentes passivos, que apenas acompanham e seguem docilmente o estabelecido.

Sendo passivamente reprodutores da ordem social estabelecida, os professores subtraem de seu trabalho a importância para a transformação do indivíduo e da sociedade. Mashiba e Gasparin (2013, p. 10139) “defendem que pensar a formação de professores na contemporaneidade exige um olhar para o educando que se quer formar, pois o professor em formação precisa vislumbrar o cidadão que se deseja para a atual sociedade”. Essa afirmação dos autores faz emergir o raciocínio segundo o qual, ao se pensar educar para a emancipação, é preciso considerar a experiência e a imaginação, objetivando ultrapassar o pensamento linear e formal. "O indivíduo deve ser educado para orientar-se no mundo, visando superar a adaptação, concentrando suas forças para a contradição e a resistência" (MASHIBA; GASPARIN, 2013, p. 10140). 
A formação inicial ou continuada de professores, enquanto categoria não material, na perspectiva adorniana, deve criar espaços para a autorreflexão, a fim de permitir o pensamento autônomo e efetivar pessoas emancipadas.

A autorreflexão possibilita um distanciamento do sujeito em relação tanto ao objeto quanto a si mesmo, uma vez que o sujeito, ao se confundir com o objeto, perde a reflexão do objeto e a autorreflexão que esta propicia, perdendo-se num emaranhado de heteronomia. Assim, na formação de professores, inicial e/ou continuada, a presença da autorreflexão se faz determinante como instrumento para o alcance da autonomia e emancipação do indivíduo.

Para Adorno (1995), a educação escolar se afastou do seu objetivo essencial, ou seja, promover o domínio pleno do conhecimento e a capacidade de reflexão. A escola se transformou em uma instituição mecânica que trata o ensino como mercadoria, anulando os valores do desenvolvimento da autorreflexão e da autonomia humana. Desse modo, Adorno critica a escola por ela legitimar a massificação do pensamento e deformar a consciência, sacrificando a individualidade.

Nessa perspectiva, entendemos a emancipação na formação de professores, para além dos conhecimentos técnicos da profissão e das demandas do mercado, como uma formação comprometida com humanização dos futuros profissionais para a solidariedade, a cooperação, a justiça, uma educação que negue a subserviência que conduz à exploração, ao poder, à guerra, à destruição da humanidade.

Então, a formação de professores deveria ter em seu currículo conteúdos que permitissem a produção de uma consciência verdadeira, percepção crítica da lógica social dominante, o que conduz a um nível superior de consciência, possibilitando ao indivíduo um pensamento autônomo no qual ele se comportasse a partir de seu próprio pensar. Essa ação metodológica criaria espaços nos cursos de formação de professores voltados para uma didática consistente que permitisse a autorreflexão com vistas à autonomia, garantindo à educação seu objetivo de formar para a emancipação.

Adorno (1995), discorrendo sobre o poder educativo do esclarecimento e do pensamento autorreflexivo no processo de formação para a emancipação humana, afirma que tornar o homem sensível e solidário é tarefa da educação.

O esclarecimento das forças de dominação em sua acentuada ação midiática favorece a semiformação do indivíduo, subtraindo sua subjetividade e o conduzindo a um pensamento e 
ação de massa. $\mathrm{O}$ esclarecimento fortalece a resistência para a ruptura com a subordinação inculcada para sujeição do indivíduo. Adorno e Horkheimer (1985, p. 47) afirmam que, pela "mediação da sociedade total, que engloba todas as relações e emoções, os homens se reconvertem exatamente naquilo contra o que se voltara a lei evolutiva da sociedade: meros seres genéricos, iguais uns aos outros pelo isolamento na coletividade governada pela força”.

O conhecimento da estrutura social, do currículo e dos conteúdos de ensino submetidos à autorreflexão e reflexão crítica pode favorecer a formação do professor para a emancipação. A concepção de formação em Adorno é uma característica essencial do sujeito humano,

como a construção das forças independentes mais profundas do indivíduo como um elemento desengajado e indiviso da totalidade da existência, forças que tornavam possível que escapasse dos processos padronizadores dominantes e das manipulações das hierarquias hegemônicas. (GUR-ZE'EV, 2009, p.13)

Esse pensamento de Adorno implica, para a formação de professores, a oportunidade de reflexão crítica da sociedade e a possibilidade de libertação do pensamento cativo pela indústria cultural presente em uma sociedade administrada.

Em uma perspectiva adorniana de formação de professores, a reflexão crítica da sociedade manifesta resistência à hegemonia e à perda da singularidade e expressa romper com as amarras mental e emocional intencionalmente veiculadas nos meios midiáticos que aprisionam a autonomia no exercício da própria vontade do indivíduo.

A reflexão crítica do determinismo social possibilita ao futuro professor ou professor em formação transcender a alienação que retira de si a autonomia. $\mathrm{O}$ desvendamento das relações de poder beneficia experiências para o conhecimento de si mesmo e da sociedade, vinculando o pensar ao sentir e a intelectualidade à afetividade e à sensibilidade.

Adorno afirma que a emancipação ocorre com uma educação para a contestação e resistência às barbáries sociais de desumanização. A educação deve dotar o indivíduo de conhecimentos epistemológicos e políticos que lhes confira condições de melhoria de sua realidade. A autonomia solicita reflexão e experiências formativas nessa direção. 
A inserção de conceitos adornianos em ações de formação inicial e continuada de professores pode contribuir para o desenvolvimento de um pensamento autônomo, a fim de efetivar a emancipação do indivíduo.

A formação de professores, crítica e capaz de fomentar o processo de resistência à dominação e à massificação, é condição atual para a escolarização de crianças e jovens, a fim de que desenvolvam a autonomia e a emancipação no lugar da adaptação e do adestramento.

Nesse sentido, a formação docente deve possibilitar experiências formativas, por meio de análise crítica da realidade, que permitam esclarecer os artifícios encerrados nos conteúdos veiculados nas mídias de alcance de massas, os quais, muitas vezes, encaminham, com suas mensagens subliminares, à visão ingênua de uma sociedade justa, embora em presença de todos os crimes, injustiças e exploração no cotidiano da vida social - uma formação que contemple uma reflexão crítica da sociedade e também uma autorreflexão na qual a subjetividade seja posta em evidência.

A crítica da educação e a possibilidade de uma outra educação para a emancipação do indivíduo, voltada para a solidariedade, eram os compromissos políticos de Adorno.

\section{Considerações finais}

As reflexões presentes neste texto buscaram ampliar as discussões em torno da complexa tarefa de formar uma consciência enquanto necessidade política, ou seja, a emancipação humana a partir da autonomia do indivíduo. A educação para a emancipação se efetiva no processo de individualização por meio da autorreflexão e do esclarecimento.

A presença de categorias adornianas na formação do professor pode contribuir para uma educação emancipatória, considerando que:

- o esclarecimento da hegemonia da ciência e da religião reinante em momento histórico social no século XVIII encerra o poder de libertar as pessoas por meio da educação, do estudo, da leitura, da capacidade de reflexão crítica e do entendimento racional do mundo;

- a formação para a promoção da capacidade de refletir e de tomar decisões com autonomia liberta o indivíduo da automação e da reificação;

- na experiência formativa estão envolvidos sentidos e pensamento que necessitam ter continuidade para serem assimilados pela consciência; 
- na práxis, teoria e prática são formativas, trazem a reflexão teórica político-social, para a transformação das injustiças sociais;

- a autorreflexão é a possibilidade de o indivíduo resistir à semiformação e à massificação para que não se deixe manipular por uma sociedade administrada;

- a reflexão crítica confere ao indivíduo a possibilidade de pensar a sociedade dialeticamente, desvelando o aparente e decifrando as relações de poder que permeiam a vida social.

Uma formação de professores que se queira autônoma deve concentrar seus esforços para o esclarecimento e a autorreflexão que possibilitem o livre pensar e as práticas docentes autônomas em uma sociedade subsumida pelos interesses econômicos e que anda na contramão de uma formação docente esclarecida e autorreflexiva.

A emancipação na formação, para além dos conhecimentos técnicos da profissão e das demandas do mercado, requer um comprometimento com a humanização dos futuros professores e dos professores para a solidariedade, a cooperação e a justiça, ademais de uma educação que nega a subserviência que conduz à exploração, ao poder, à guerra e à destruição da humanidade.

Não temos a intenção de esgotar o tema em foco, dadas sua importância e complexidade, mas, ao tratarmos dos conceitos de esclarecimento e autorreflexão para uma formação emancipatória, almejamos que as reflexões aqui expostas possam incentivar novas investigações sobre a importância da emancipação na formação de professores para o enfrentamento dos desafios de viver em uma sociedade e educação contraditórias.

\section{Referências}

ADORNO, T. W. Educação e emancipação. Tradução Wolfgang Leo Maar. 3. ed. Rio de Janeiro: Paz e Terra, 2010.

ADORNO, T. W. Notas Marginais sobre Teoria e Práxis. In: ADORNO, T. W. Palavras e Sinais: modelos críticos. Petrópolis, RJ: Vozes, 1995.

ADORNO, T. W.; HORKHEIMER, M. Dialética do Esclarecimento: fragmentos filosóficos. Trad. Guido Antônio de Almeida. Rio de Janeiro: Jorge Zahar Ed. 1985.

COHN, G. (org.). Theodor W. Adorno: Sociologia. Trad. Flávio Kothe, Aldo Onesti e Amélia Cohn. 2 ed. São Paulo: Ática, 1994. 
GUR-ZE'EV, I. A Formação (Bildung) e a Teoria Crítica Diante da Educação Pós-Moderna. In: PUCCI, B.; ALMEIDA, J. de; LATÓRIA, L. A. C. N. (org.). Experiência Formativa e Emancipação. São Paulo: Nankin, 2009.

MARTINS, L. M. Formação de professores: desafios contemporâneos e alternativas necessárias. In: GUADALUPE, S.; MENDONÇA, V. P. da S. L.; MILLER, S. (org.) Marx, Gramsci e Vigotski: aproximações. Araraquara, SP: Junqueira \& Marin Editores, 2012.

MASHIBA, G. C. X.; GASPARIN, J. L. Formação de professores: para além do pensamento tutelado. In: XI CONGRESSO NACIONAL DE EDUCAÇÃO, EDUCERE. 2013, Curitiba. Anais [...]. Curitiba, 2013. Disponível em:

http://educere.bruc.com.br/CD2013/pdf/10152_5965.pdf. Acesso em: 1 fev. 2019.

PUCCI, B. Teoria Crítica e Educação. In: PUCCI, B. (org.). Teoria Crítica e Educação: a questão da formação cultural na Escola de Frankfurt. Petrópolis, RJ: Vozes; São Carlos, SP: EDUFISCAR, 1994.

PUCCI, B. Teoria crítica e educação: contribuições da teoria crítica para a formação do professor. Espaço Pedagógico, v. 8, 2001. Disponível em:

http://www.unimep.br/ bpucci/teoria-critica-e-educacao.pdf. Acesso em: 13 maio 2017.

PUCCI, B.; RAMOS-DE-OLIVEIRA, N. O enfraquecimento da experiência na sala de aula. Pro-Posições, Campinas, v. 18, n. 1, p. 41-50, jan./abr. 2007.

RUZ, J. Teoria Crítica e Educação. Perspectiva. v. 1, n. 3, p. 9-50. jul./dez. 1984. Disponível em: https://periodicos.ufsc.br/index.php/perspectiva/article/view/8978/8326I. Acesso em: 19 maio 2017.

VILELA, R. A. T. A Teoria Crítica da Educação de Theodor Adorno e sua apropriação para análise das questões atuais sobre currículo e práticas escolares. Belo Horizonte: CNPQ (Relatório de Pesquisa), 2006.

VILELA, R. A. T. Críticas e possibilidades da educação e da escola na contemporaneidade: lições de Theodor Adorno para o currículo. Educação em Revista, Belo Horizonte, n. 45, jun. 2007. Disponível em: http://www.scielo.br/scielo.php?script=sci_arttext\&pid=S010246982007000100012. Acesso em: 11 jun. 2018.

ZUIN, A. A. S.; PUCCI, B.; RAMOS-DE-OLIVEIRA, N. Adorno. O poder educativo do pensamento crítico. 5. ed. Petrópolis, RJ: Vozes, 2012.

Enviado em: 15/09/2019

Revisado em: 28/02/2021

Aprovado em: 04/03/2021

Publicado em: 15/06/2021 